\title{
The Percentage of Vaccine Hesitancy among Married Individuals in Times of the COVID-19 Pandemic: A Cross Sectional Study in Riyadh City, Kingdom of Saudi Arabia
}

\author{
Mahmoud Mahmoud ${ }^{\mathrm{a}}$ Maha M. Alanazi ${ }^{\mathrm{b}}$ Maha S. Albarrak ${ }^{\mathrm{b}}$ Najd K. Aljarba $^{\mathrm{b}}$ \\ Nehal G. Almutairib \\ associate Professor, College of Medicine, Imam Muhammad Ibn Saud Islamic University, Riyadh, Saudi Arabia; \\ ${ }^{b}$ College of Medicine, Imam Muhammad Ibn Saud Islamic University, Riyadh, Saudi Arabia
}

\section{Keywords}

Attitude $\cdot$ COVID-19 $\cdot$ Hesitancy $\cdot$ Married parents $\cdot$ Saudi Arabia $\cdot$ Vaccination

\begin{abstract}
Background: Vaccines are largely regarded as one of medicine's greatest breakthroughs, yet vaccination rates have been declining in many parts of the world in recent years. Although there are numerous contributing variables to decreased vaccination rates, it is critical to evaluate the impact of the relevant factors. Also, because we are in the midst of a sad epidemic and vaccination for COVID-19 is critical to maintaining public health and limiting the virus's spread, there is a risk of vaccine rejection on the horizon. Methods: Five hundred and fourteen married Riyadh inhabitants aged 18 years and over were issued an online Web-based survey. The research took place from June to October 2020. The study calculates the percentage of vaccination apprehension and analyzes immunization attitudes and knowledge. It also contrasts the participants' attitudes regarding vaccines before and during the COVID-19 global pandemic, as well as the associated causes for vaccine reluctance and rejection. Result: The majority of the respondents (48.1\%) were be-
\end{abstract}

karger@karger.com www.karger.com/sjh

Karger $\frac{1}{6}$
(C) 2021 The Author(s)

Published by S. Karger AG, Basel

This is an Open Access article licensed under the Creative Commons Attribution-NonCommercial-4.0 International License (CC BY-NC) (http://www.karger.com/Services/OpenAccessLicense), applicable to the online version of the article only. Usage and distribution for commercial purposes requires written permission. tween $37-47$ and $26-36$ years of age (37.5\%). Females (80\%) made up the majority of the group. Around $66.3 \%$ of participants have a bachelor's degree, and $80.8 \%$ have an average monthly income. During the pandemic, $38.5 \%$ of participants said they do not want to be vaccinated. When comparing vaccine-hesitant participants' sociodemographic characteristics, it was discovered that the percentage of vaccine-hesitant participants was significantly higher in the younger age-group ( $<36$ years), those who had been married for more than 10 years, those with 1-3 children $(p<$ $0.001)$, and those who did not work ( $p=0.002)$. Conclusion: The percentage of people who are hesitant to get vaccinated has grown by $5.2 \%$ from the previous level, and the level of reluctance has increased by $2.3 \%$.

(C) 2021 The Author(s).

Published by S. Karger AG, Basel

\section{Introduction}

Vaccination is one of the "Ten Great Public Health Achievements of the 20th Century" [1]. Vaccinations are an important part of basic health care and a fundamental human right as they help prevent and control infectious 
disease epidemics [2]. Vaccinations are also one of the most important and effective strategies to prevent disease by assisting the immune system in recognizing and eliminating invaders such as bacteria and viruses. As a result, vaccination has become an important aspect of public health and disease prevention. Vaccines lower the incidence of vaccine-preventable illnesses (VPDs) and prevent death from VPD, which is estimated to be responsible for 2.5 million deaths per year [3]. Vaccine hesitancy has become a global issue, despite the tremendous achievements of vaccines and the global comprehensive effort to improve vaccine usage and acceptability. Vaccine hesitancy is defined by the World Health Organization (WHO) as a delay in accepting or refusing vaccines notwithstanding the availability of immunization services [4]. Unfortunately, it remains a contentious issue in society, with many advocates and opponents.

The vaccine rejection movement has recently grown in popularity; this movement believes that vaccines do more harm than good to the health of children who get them [5]. The vaccine refusal movement's hypothesis can also be linked to how vaccinations are presented by businesses, the press, and social media. Other factors, such as religious beliefs, have also contributed to the vaccine refusal movement. Religious factors, for example, have been used as an excuse in some countries to forgo vaccination, resulting in vaccine-preventable disease outbreaks [6]. Vaccine hesitancy has a significant impact on herd immunity, which the WHO has worked hard to address because global communities are now more connected than ever, increasing the risk of pathogen transmission as it focuses on dispelling myths and misconceptions about immunization [7]. When it comes to the impact of vaccination hesitancy, it can put an individual or a community at risk of VPD, which can jeopardize herd immunity. Parental vaccine acceptance and adherence, on the other hand, have an impact on public health outcomes and play a role in vaccine success [8]. Despite its influence on the population, vaccination reluctance has received little attention to date despite the fact that it could extend the epidemic and need unnecessary precautions [9]. Furthermore, in recent years, Saudi Arabia has seen an increase in the number of people who are afraid to get vaccinated, which may be affected by social media posts. Due to the myths and misconceptions about vaccination that have arisen, these individuals have questioned the safety, efficacy, and necessity of immunizations [10]. The purpose of this study is to determine the prevalence of vaccine hesitancy among married couples in the Riyadh region aged 18 years and over, as well as to assess vaccina-

Percentage of Vaccine Hesitancy in Times of the COVID-19 Pandemic tion awareness and perception in this population and also to outline the possible causes of vaccination reluctance and rejection.

\section{Materials and Methods}

Study Design

A cross-sectional study was undertaken in the Riyadh region, the capital of Saudi Arabia.

\section{Study Population and Sampling}

According to the data from the general authority of statics 2017, married Saudis from the age of 15 years and over were $1,789,156$ persons [11], by using this data. We have calculated our sample with $95 \%$ level of confidence and a precision rate of 0.05 , and the estimated sample size was 427 Person. A convenient sampling method was applied to recruit the required sample. The study was conducted from June 2020 to October 2020 during the COVID-19 pandemic. The response rate during the study period shows 514 complete answers from married citizens aged 18 years and over.

\section{Study Questionnaire}

The questionnaire was a self-administered survey that was sent with different social media platforms like WhatsApp and Twitter. The study excluded non-Riyadh citizens, non-Saudi, and single participants, also any participants younger than 15 years. The participants were asked to answer an Arabic questionnaire to estimate the percentage of participants who are vaccine-hesitant and to assess the perceptions and knowledge regarding immunization among married Riyadh citizens from the age of 18 years and over. The study questionnaire contained 10 demographic questions and 12 questions regarding the participant's current vaccination status, the perceived side effects, the incidences of the disease due to the nonadherence toward child vaccination, and the sources of information regarding the opposition of vaccination. It also compared the participant's stance toward vaccines before and during the COVID-19 global pandemic. The participants were asked questions that were considered the study variables, which were as follows: educational status, financial status, gender, years of marriage, employment status, children count, and age $[12,13]$. A pilot sample was used to test the content validity of the questionnaire, and the test sample did not include in the final study population.

\section{Ethical Approval}

The study protocol and the questionnaire were approved by Imam Muhammad Ibn Saud Islamic University. The participants proceeded to answer the questionnaire after reading the written informed consent for being involved in the study.

\section{Data Analysis}

$\chi^{2}$ tests were applied. After conducting univariate analysis, multivariate logistic regression was undertaken to assess independent associations related to the dichotomous variables of opposition to vaccination. $p$ values $<0.05$ were considered statistically significant. All statistical analyses were performed using the Statistical Package for the Social Sciences software, for Windows (version 21; IBM, Armonk, NY, USA). 
Table 1. Sociodemographic characteristics of the participants $(n=514)$

\begin{tabular}{|c|c|}
\hline Study variables & $N(\%)$ \\
\hline \multicolumn{2}{|l|}{ Age-group } \\
\hline$\leq 36$ years & $226(43.9)$ \\
\hline$>36$ years & $288(56.1)$ \\
\hline \multicolumn{2}{|l|}{ Gender } \\
\hline Male & $103(20.0)$ \\
\hline Female & $411(80.0)$ \\
\hline \multicolumn{2}{|l|}{ Years of marriage } \\
\hline$\leq 5$ years & $99(19.3)$ \\
\hline $6-10$ years & 99 (19.3) \\
\hline$>10$ years & $315(61.5)$ \\
\hline \multicolumn{2}{|l|}{ Children, $n$} \\
\hline None & $41(8.0)$ \\
\hline $1-3$ & $227(44.2)$ \\
\hline$\geq 4$ & $246(47.9)$ \\
\hline \multicolumn{2}{|l|}{ Educational level } \\
\hline Primary & $3(0.60)$ \\
\hline Intermediate & $10(1.9)$ \\
\hline Secondary & $81(15.8)$ \\
\hline Bachelor's degree & $341(66.3)$ \\
\hline Postgraduate & $79(15.4)$ \\
\hline \multicolumn{2}{|l|}{ Partner educational level } \\
\hline Uneducated & $1(0.20)$ \\
\hline Primary & $3(0.60)$ \\
\hline Intermediate & $23(4.5)$ \\
\hline Secondary & $104(20.2)$ \\
\hline Bachelor's degree & $283(55.1)$ \\
\hline Postgraduate & $100(19.5)$ \\
\hline \multicolumn{2}{|l|}{ Monthly income level } \\
\hline Low income & $33(6.4)$ \\
\hline Average income & $423(82.3)$ \\
\hline High income & $58(11.3)$ \\
\hline \multicolumn{2}{|l|}{ Job status } \\
\hline Employed & $286(55.6)$ \\
\hline Unemployed & $228(44.4)$ \\
\hline \multicolumn{2}{|l|}{ Partner's job status } \\
\hline Employed & $421(81.9)$ \\
\hline Unemployed & $93(18.1)$ \\
\hline
\end{tabular}

\section{Results}

Five hundred and fourteen out of 734 responses were selected which match the selection criteria and completeness. The exclusion of those participants was upon the residential area as this study was specified to Riyadh city residents. Table 1 presents the sociodemographic characteristics of 514 respondents. The most common agegroup was $37-47$ years of age (48.1\%) and $26-36$ years of age (37.5\%). Females dominated the males ( $80 \%$ vs. $20 \%$ ). With regards to years in marriage, nearly $61.5 \%$ were married for more than 10 years with a little below half of them (47.9\%) having more than 4 children. Concerning
Table 2. Participants' awareness toward vaccination and percentage of vaccination hesitancy $(n=514)$

\begin{tabular}{|c|c|}
\hline Statement & $N(\%)$ \\
\hline \multicolumn{2}{|l|}{ Vaccine importance } \\
\hline Important & $315(61.3)$ \\
\hline Not important & $170(33.1)$ \\
\hline I do not know & $29(5.6)$ \\
\hline \multicolumn{2}{|l|}{ Vaccine safety } \\
\hline Safe & $264(51.4)$ \\
\hline Not safe & $183(35.6)$ \\
\hline I do not know & $67(13.0)$ \\
\hline \multicolumn{2}{|c|}{ Vaccination is important to keep the child healthy } \\
\hline Yes & $300(58.4)$ \\
\hline No & $169(32.9)$ \\
\hline I have no idea & $45(8.8)$ \\
\hline \multicolumn{2}{|c|}{ Hesitation to child vaccination } \\
\hline Yes & $177(34.4)$ \\
\hline No & $297(57.8)$ \\
\hline Sometimes & $40(7.8)$ \\
\hline \multicolumn{2}{|c|}{ Previous history of vaccination } \\
\hline Yes & $486(94.6)$ \\
\hline No & $28(5.4)$ \\
\hline \multicolumn{2}{|c|}{ Having children who underwent vaccination } \\
\hline Yes & $449(87.4)$ \\
\hline No & $65(12.6)$ \\
\hline \multicolumn{2}{|c|}{$\begin{array}{l}\text { Were you with or against vaccination before the corona } \\
\text { pandemic? }\end{array}$} \\
\hline With vaccination & $290(56.4)$ \\
\hline Against vaccination & $171(33.3)$ \\
\hline Hesitant & $53(10.3)$ \\
\hline \multicolumn{2}{|c|}{$\begin{array}{l}\text { Are you now, during the corona pandemic, for or against } \\
\text { vaccination? }\end{array}$} \\
\hline With vaccination & $251(48.8)$ \\
\hline Against vaccination & $198(38.5)$ \\
\hline Hesitant & 65 (12.6) \\
\hline
\end{tabular}

their educational attainment, more than two-thirds (66.3\%) earned bachelor's degrees. With respect to their monthly income level, 4 quarters $(80.8 \%)$ stated an average monthly income level, with more than half (55.6\%) being employed, and the majority $(81.9 \%)$ stated that their partners were also employed. Table 2 shows participant's awareness toward vaccination and the percentage of vaccine hesitancy among married individuals. Based on the results, the proportion of respondents who thought that vaccines are important, who believe that vaccines are safe, and who perceived that vaccination is important to keep the child healthy were $61.3 \%, 51.4 \%$, and $58.4 \%$, respectively. Furthermore, approximately $34.4 \%$ of the respondents were hesitant.

The percentage of participants who had a previous history of vaccination was $94.6 \%$, while the percentage of children who underwent vaccination was $87.4 \%$. On the 


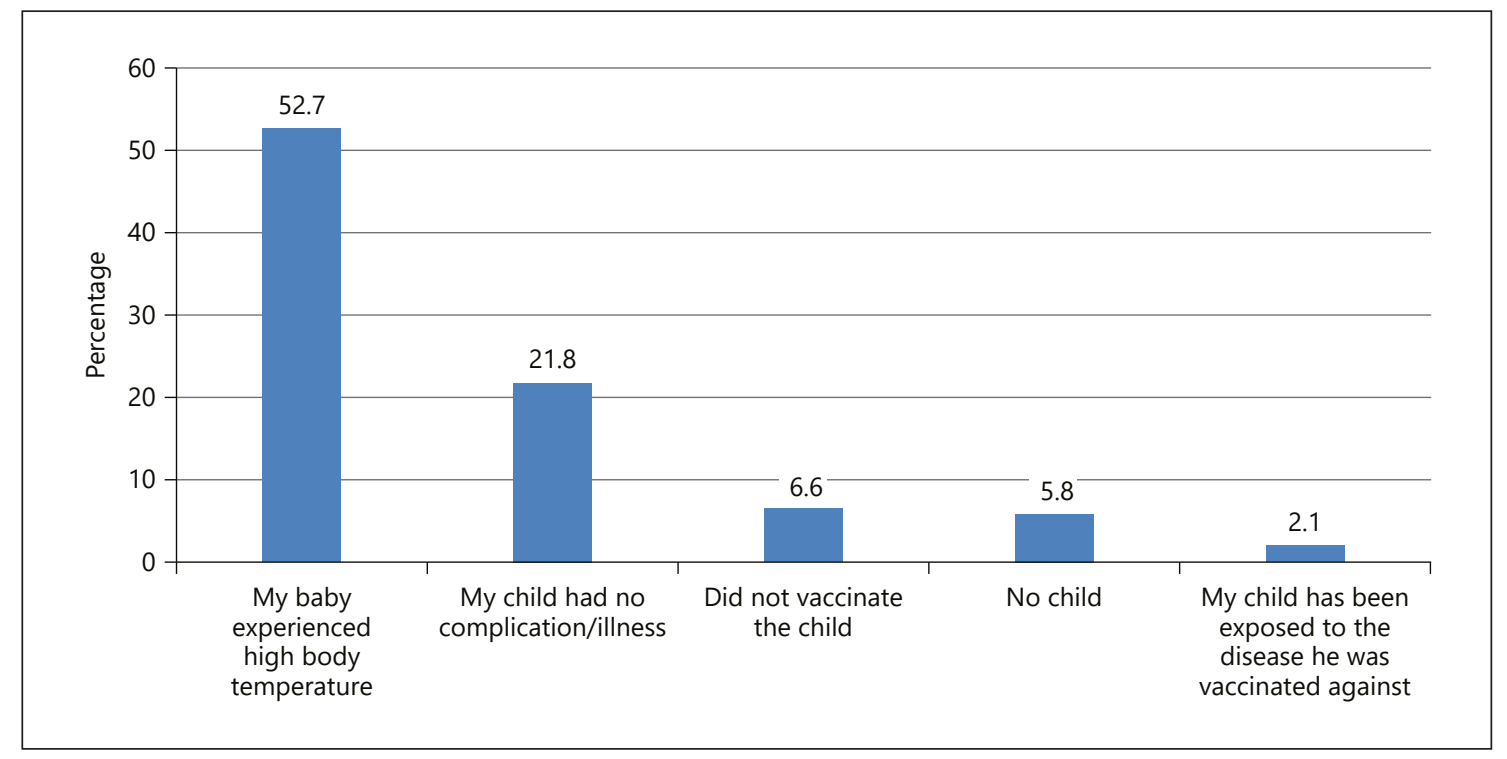

Fig. 1. Perceived side effects of child vaccination by the participants.

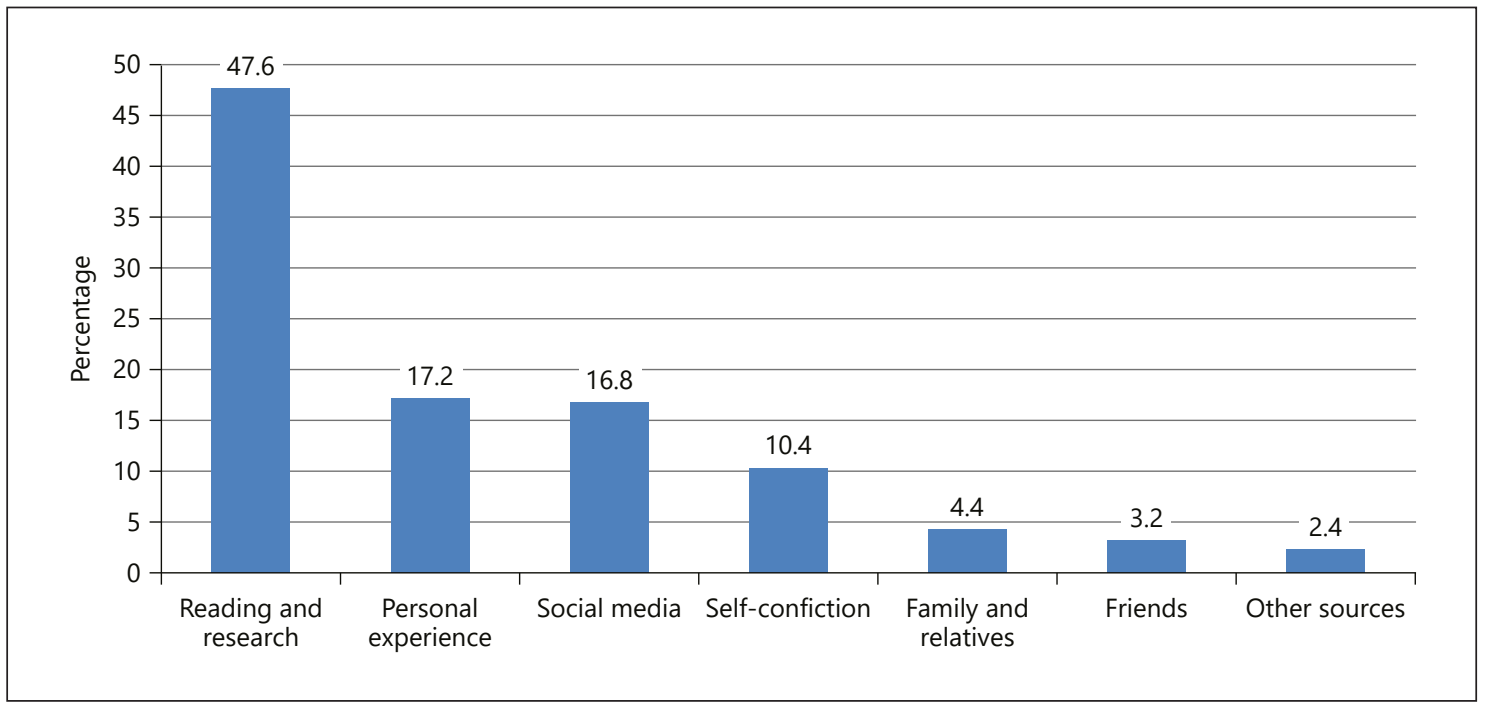

Fig. 2. Sources of information regarding vaccination hesitancy.

other hand, the percentage of participants who opposed vaccination before the pandemic was $33.3 \%$, while the estimated percentage increased to $38.5 \%$ after the pandemic.

In Figure 1, the most known side effect of child vaccination is high body temperature (50.4\%). In Figure 2, the most frequently mentioned sources of information regarding opposition to vaccination are reading and searching the websites (51.3\%), followed by social media (16.1\%) and personal experience (15.9\%), while friends were the least (2.4\%), and others stated their child had no compli- cation or illness (18.4\%). When comparing participants who are vaccine-hesitant among the sociodemographic characteristics of participants, it was found that the percentage of these individuals were significantly higher in the younger age-group ( $\leq 36$ years) $\left(X^{2}=31.924 ; p<\right.$ $0.001)$ and higher in the male gender $\left(X^{2}=6.573 ; p=\right.$ $0.010)$, those who were in more $>10$ years of marriage $\left(X^{2}=40.378 ; p<0.001\right)$, those with $1-3$ children $\left(X^{2}=\right.$ $26.439 ; p<0.001)$, and those who were not working $\left(X^{2}=\right.$ 8.704; $p=0.003$ ) (Table 3). 
Table 3. Influence of vaccine hesitancy in relation to participants sociodemographic characteristics $(n=514)$

\begin{tabular}{|c|c|c|c|c|}
\hline Factor & $\begin{array}{l}\text { Opposite vaccine, } N(\%), \\
(n=198)\end{array}$ & $\begin{array}{l}\text { Hesitant, } N(\%), \\
(n=316)\end{array}$ & $x^{2}$ & $p$ value $^{\S}$ \\
\hline \multicolumn{5}{|l|}{ Age-group } \\
\hline$\leq 36$ years & $118(59.6)$ & $108(34.2)$ & \multirow{2}{*}{31.924} & \multirow{2}{*}{$<0.001^{* *}$} \\
\hline$>36$ years & $80(40.4)$ & $208(65.8)$ & & \\
\hline \multicolumn{5}{|l|}{ Gender } \\
\hline Male & $51(25.8)$ & $52(16.5)$ & \multirow{2}{*}{6.573} & \multirow{2}{*}{$0.010^{* *}$} \\
\hline Female & $147(74.2)$ & $264(83.5)$ & & \\
\hline \multicolumn{5}{|l|}{ Years of marriage } \\
\hline 5 years or less & $62(31.3)$ & 37 (11.7) & \multirow{3}{*}{40.378} & \multirow{3}{*}{$<0.001^{* *}$} \\
\hline $6-10$ years & $46(23.2)$ & $53(16.8)$ & & \\
\hline$>10$ years & $90(45.5)$ & $226(71.5)$ & & \\
\hline \multicolumn{5}{|l|}{ Children, $n$} \\
\hline No children & $23(11.6)$ & $18(5.7)$ & \multirow{3}{*}{26.439} & \multirow{3}{*}{$<0.001^{* *}$} \\
\hline $1-3$ years & $108(54.5)$ & $119(37.7)$ & & \\
\hline$\geq 4$ years & $67(33.8)$ & $179(56.6)$ & & \\
\hline \multicolumn{5}{|l|}{ Educational level } \\
\hline Secondary or below & $33(16.7)$ & $61(19.3)$ & \multirow[b]{2}{*}{0.567} & \multirow{2}{*}{0.452} \\
\hline Bachelor degree or higher & $165(83.3)$ & $255(80.7)$ & & \\
\hline \multicolumn{5}{|l|}{ Partner educational level } \\
\hline Secondary or below & $44(22.2)$ & $87(27.5)$ & \multirow{2}{*}{1.807} & \multirow{2}{*}{0.179} \\
\hline Bachelor degree or higher & $154(77.8)$ & $229(72.5)$ & & \\
\hline \multicolumn{5}{|l|}{ Monthly income level } \\
\hline Low income & $14(7.1)$ & $19(6.0)$ & \multirow{3}{*}{0.499} & \multirow{3}{*}{0.779} \\
\hline Average income & $160(80.8)$ & $263(83.2)$ & & \\
\hline High income & $24(12.1)$ & $34(10.8)$ & & \\
\hline \multicolumn{5}{|l|}{ Currently employed } \\
\hline Yes & $94(47.5)$ & $192(60.8)$ & \multirow[b]{2}{*}{8.704} & \multirow[b]{2}{*}{$0.003^{* *}$} \\
\hline No & $104(52.5)$ & $124(39.2)$ & & \\
\hline \multicolumn{5}{|l|}{ Partner currently employed } \\
\hline Yes & $157(79.3)$ & $264(83.5)$ & \multirow{2}{*}{1.485} & \multirow{2}{*}{0.223} \\
\hline No & $41(20.7)$ & $52(16.5)$ & & \\
\hline
\end{tabular}

A multivariate regression analysis was subsequently conducted to determine the factors independently associated with opposition to vaccination. Based on the results, it was observed that those in the older group ( $>36$ years) were less likely to oppose vaccination (adjusted odds ratio $[\mathrm{AOR}]=0.371 ; 95 \%$ confidence interval $[\mathrm{CI}]=0.214-$ $0.643 ; p<0.001)$. It was also observed that those who have $>4$ children were less likely to oppose vaccination (AOR $=0.487 ; 95 \% \mathrm{CI}=0.278-0.856 ; p<0.012)$. Those who were currently employed were less likely to oppose vaccination $(\mathrm{AOR}=0.527 ; 95 \% \mathrm{CI}=0.340-0.818 ; p<0.004)$, suggesting that the odds of opposition to vaccination for those in the older group ( $>36$ years) were likely to decrease by $60 \%(\mathrm{AOR}=0.400 ; 95 \% \mathrm{CI}=0.251-0.639 ; p<$ $0.001)$. It was also predicted that the odds of opposition to vaccination for those participants with 4 or more children would likely be decreased by $50 \%$ (AOR $=0.498$;
95\% CI $=0.284-0.872 ; p=0.015)$, while in participants who were currently employed, the odds for vaccine hesitancy could be decreased by nearly $60 \%$ (AOR $=0.589$; $95 \% \mathrm{CI}=0.388-0.892 ; p=0.013)$. On the other hand, years of marriage did not show a significant impact on vaccine hesitancy after adjustment to the regression model (Table 4).

A minor percentage of the participants stated their reasons behind vaccine rejection and hesitancy. Around $23.6 \%$ of the parents rejected vaccines due to the harmful substances it contains. However, $13.5 \%$ believe that vaccines are for profit and commercials purposes only. Also, other participants reported a rejection due to it is side effects (12.7\%) and complications (11.4\%). In addition, $2.1 \%$ have a lack of trust in doctors, and $1.3 \%$ lack trust in the medical staff and the medical centers that provide vaccines. Moreover, $6.3 \%$ of the participants 
Table 4. Multivariate regression analysis to determine the independent significant factor associated with vaccine hesitancy $(n=514)$

\begin{tabular}{llll}
\hline Factor & AOR & $95 \% \mathrm{Cl}$ & $p$ value \\
\hline $\begin{array}{l}\text { Age-group } \\
\quad \text { 36 years }\end{array}$ & Ref & & \\
$\quad$ >36 years & 0.371 & $0.214-0.643$ & $<0.001^{* *}$ \\
$\begin{array}{l}\text { Gender } \\
\quad \text { Male }\end{array}$ & Ref & & \\
$\quad$ Female & 0.647 & $0.382-1.096$ & 0.105 \\
$\begin{array}{l}\text { Years of marriage } \\
\quad \text { years or less }\end{array}$ & Ref & & \\
$\quad$ 6-10 years & 0.657 & $0.318-1.359$ & 0.257 \\
$\quad$ 10 years & 0.938 & $0.491-1.792$ & 0.847 \\
$\begin{array}{l}\text { Children, } n \\
\quad \text { No children }\end{array}$ & Ref & & \\
$\quad$ 1-3 years & 0.688 & $0.271-1.748$ & 0.432 \\
$\quad$ (4 years & 0.487 & $0.278-0.856$ & $0.012^{* *}$ \\
Currently employed & & & \\
$\quad$ Yes & 0.527 & $0.340-0.818$ & $0.004^{* *}$ \\
$\quad$ No & Ref & & \\
\hline
\end{tabular}

AOR, adjusted odds ratio; $\mathrm{Cl}$, confidence interval. ** Significant at the $p<0.05$ level.

mistrust the methods of making and storing vaccines, and $1.7 \%$ oppose vaccines due to hygienic and sterilization issues.

\section{Discussion}

To our knowledge, this is the first study in Saudi Arabia that has identified an association between demographic variables and vaccination hesitation, with a percentage of parents who are vaccine-hesitant in Riyadh, before and after the COVID-19 pandemic. According to the findings, $34.4 \%$ of the respondents were unsure. The percentage of these people was found to be significantly greater in the younger age-group (36 years), the male gender, and those who were unemployed. Our findings are nearly double those of a 2018 study done in Riyadh, in which the reluctance rate was determined to be $15.5 \%$, with the percentages being notably higher in the middle age-group (>30), female gender, and those with a high educational degree. [14], whereas a study conducted in Riyadh in 2019 found that the proportion of hesitant parents in the sample community did not exceed $20 \%$ [10].

Reading, searching the Internet, and social media were the most frequently mentioned sources of being against vaccinations, accounting for approximately $67 \%$ of participant sources compared to a study from Riyadh that found that the majority of their participants (56\%) rely on the Internet and social media for information [14]. When comparing our findings to those of the Riyadh study, it was discovered that the main factor associated with both parents' hesitancy and incomplete vaccination status was the belief that vaccines are not important, whereas our findings revealed that only a small percentage of participants stated that vaccines are not essential or have harmful side effects and complications [6].

In a cross-sectional survey of 731 participants in the Taif region of Saudi Arabia, over 3 quarters of parents believed that vaccination of their children is extremely important, especially during immunization campaigns, compared to $61.3 \%$ in our study [15]. Furthermore, parents' attitudes regarding immunization were good, with the exception of $39.4 \%$ of cases including side effects, which are only reported in this study [15].

In Arar, northern Saudi Arabia, another cross-sectional community-based study with 367 participants was conducted to investigate parents' opinions toward child immunization. Most parents (88.3\%) believe that immunizing their children is necessary, compared to $61.3 \%$ in our survey. However, $6.8 \%$ were aware that immunization can cause adverse effects such as fever as the majority of studies, including ours, mention [16].

\section{Limitations}

The current study had certain limitations. First, because the majority of the participating parents were females, our study population was drawn from a convenient sample, which resulted in sample characteristics that differed from those expected. Second, the study was done solely in the Riyadh region. As a result, the findings cannot be applied to the entire population, and we may have shown bias in our estimations due to a possible relationship between the place of residency and hesitancy. Despite the difficulty of dealing with various sorts of datagathering techniques during the COVID-19 epidemic, the researchers attempted to cover the majority of the Riyadh city clusters by using utilizing various communication tools and according to their areas of residence.

\section{Implication Policy}

- Create a central immunization database that is accessible to all associated sites in order to demonstrate effective outcomes and safety precautions.

- Improve premarital activities and parenting education in order to increase compliance and response rates. 
- Improved communication tools in the social media to correct incorrect beliefs.

- Strengthening the legal framework to safeguard the public from vaccine skeptics.

\section{Conclusion}

Finally, low vaccine awareness is a serious hazard to public health, especially during pandemics like COVID-19. In our research, we discovered that vaccination apprehension is rather high in Riyadh and that it rose during the COVID-19 pandemic. As a result, educational and awareness initiatives, as well as related public health intervention programs, are critical.

\section{Acknowledgments}

The authors would like to acknowledge Mr. Rommel R. Acunin for his assistance in data interpretation and Dr. Sami Abdo Radman Al-dubai for his help in reviewing the research.

\section{Statement of Ethics}

Ethical approval for this study's conduction and data collection were reviewed and approved by the Institutional Review Board (IRB) committee of Al-Imam Muhammad Ibn Saud Islamic University, Chairman Prof. AbdulAziz Al-Akaabba, and Dr. Arezki Azzi (Project Approval Number: 35-2020). Written informed consent was obtained from all participants.

\section{Conflict of Interest Statement}

The authors declare that they have no competing interests.

\section{Funding Sources}

The authors report no funding.

\section{Author Contributions}

M.A.M. was the supervisor of this project. N.G.M. generated the vaccine hesitancy concept, and M.A.M., M.M.A., M.S.A., and N.K.J. attached the COVID-19 pandemic idea and chose the research design. M.M.A., M.S.A., N.K.J., and N.G.A. were responsible for data collection, data analysis, data interpretation, writing the literature review, writing the proposal, reviewing and editing the proposal, writing the manuscript, and reviewing and proofreading the manuscript. The final revision and verification of the manuscript before submission were done by M.A.M., M.M.A., M.S.A., N.K.J., and N.G.A.

\section{Data Availability Statement}

The datasets analyzed during the current study are available from the corresponding author on reasonable request. Due to data protection restrictions and participant confidentiality, we do not make participant data publicly available.

\section{References}

1 Centers for Disease Control and Prevention. CDC. Ten great public health achievements: the United States, 1900-1999. MMWR. 1999 Apr 2;48(12):241.

2 Vaccines and immunization [Internet].

3 Centers for Disease Control Global Health. Global health security: immunization; 2021.

4 World Health Organisation. Report of the sage working group on vaccine hesitancy; 2014.

5 Hussain A, Ali S, Ahmed M, Hussain S. The anti-vaccination movement: a regression in modern medicine. Cureus. $2018 \mathrm{Jul} ; 10(7)$ : e2919.

6 Pelčić G, Karačić S, Mikirtichan GL, Kubar OI, Leavitt FJ, Tai MC, et al. Religious exception for vaccination or religious excuses for avoiding vaccination. Croatian medical journal. 2016 Oct;57(5):516.

7 Clift K, Rizzolo D. Vaccine myths and misconceptions. JAAPA. 2014 Aug 1;27(8):21-6.
8 Dabla-Norris E, Khan H, Lima F, Sollaci A. Who doesn't want to be vaccinated? Determinants of vaccine hesitancy during covid-19; 2021.

9 Nabet BB, Gable JL, Eder JP, Feemster KA. Addressing vaccine hesitancy to protect children and communities against preventable diseases. Policy lab at children's hospital Of Philadelphia; 2017.

10 Alsubaie S, Gosadi I, Alsaadi B, Albacker N, Bawazir M, Bin-Daud N, et al. Vaccine hesitancy among Saudi parents and its determinants; 2021.

11 "Saudi Arabia Population Characteristics in 2017”. The general authority of statics; 2020. Available from: www.stats.gov.sa/ar/5655.

12 Napolitano F, D’Alessandro A, Angelillo IF. Investigating Italian parents' vaccine hesitancy: a cross-sectional survey. Hum Vaccin Immunother. 2018 Jul 3;14(7):1558-65.
13 Du F, Chantler T, Francis MR, Sun FY, Zhang $\mathrm{X}$, Han $\mathrm{K}$, et al. The determinants of vaccine hesitancy in China: a cross-sectional study following the Changchun Changsheng vaccine incident. Vaccine. 2020 Nov 3;38(47): 7464-71.

14 Al-Saeed G, Riszk T, Al-Saeed K, Al-Ramadina BA, Al-Saeed I. Vaccine hesitancy prevalence and correlates in Riyadh, Saudi Arabia; 2018. Available from: https://www.actascientific.com/ASPE/pdf/ASPE-01-0003.pdf.

15 (Pdf) knowledge and attitudes on childhood vaccination a survey among saudi parents in taif region, saudi arabia [internet]. Researchgate. 2014

16 Alruwaili A, Abo El-fetoh N, Alruwaili T, Alanazi W, Alhazmi H, Alanazi N, et al. Knowledge, attitude and practice of the parents regarding child vaccinations in arar, Northern Saudi Arabia. Ejhm J. 2018. 